OPEN ACCESS

Edited by:

Diana Dudziak

Universitätsklinikum Erlangen,

Germany

Reviewed by:

Jan Lunemann,

University of Zurich, Switzerland

Sven Burgdorf,

Universität Bonn, Germany

*Correspondence:

Yvette van Kooyk

Y.vanKooyk@vumc.n

Specialty section:

This article was submitted to Antigen Presenting Cell Biology,

a section of the journal

Frontiers in Immunology

Received: 31 August 2018 Accepted: 14 November 2018 Published: 07 December 2018

Citation:

Lübbers J, Rodríguez E and van Kooyk Y (2018) Modulation of Immune Tolerance via Siglec-Sialic Acid Interactions. Front. Immunol. 9:2807. doi: 10.3389/fimmu.2018.02807

\section{Modulation of Immune Tolerance via Siglec-Sialic Acid Interactions}

\author{
Joyce Lübbers, Ernesto Rodríguez and Yvette van Kooyk* \\ Molecular Cell Biology and Immunology, Amsterdam UMC, Vrije Universiteit Amsterdam, Cancer Center Amsterdam, \\ Amsterdam Infection and Immunity Institute, Amsterdam, Netherlands
}

One of the key features of the immune system is its extraordinary capacity to discriminate between self and non-self and to respond accordingly. Several molecular interactions allow the induction of acquired immune responses when a foreign antigen is recognized, while others regulate the resolution of inflammation, or the induction of tolerance to self-antigens. Post-translational signatures, such as glycans that are part of proteins (glycoproteins) and lipids (glycolipids) of host cells or pathogens, are increasingly appreciated as key molecules in regulating immunity vs. tolerance. Glycans are sensed by glycan binding receptors expressed on immune cells, such as C-type lectin receptors (CLRs) and Sialic acid binding immunoglobulin type lectins (Siglecs), that respond to specific glycan signatures by triggering tolerogenic or immunogenic signaling pathways. Glycan signatures present on healthy tissue, inflamed and malignant tissue or pathogens provide signals for "self" or "non-self" recognition. In this review we will focus on sialic acids that serve as "self" molecular pattern ligands for Siglecs. We will emphasize on the function of Siglec-expressing mononuclear phagocytes as sensors for sialic acids in tissue homeostasis and describe how the sialic acid-Siglec axis is exploited by tumors and pathogens for the induction of immune tolerance. Furthermore, we highlight how the sialic acid-Siglec axis can be utilized for clinical applications to induce or inhibit immune tolerance.

Keywords: mononuclear phagocytes, dendritic cells, macrophages, Siglecs, tolerance, inflammation, sialic acid, cancer

\section{HIGHLIGHTS}

- Siglecs have an immune modulatory effect on TLR signaling.

- Sialic acids can be presented by pathogens through synthesis of "mimic" structures or the novo synthesis for survival advantage.

- Hyper sialic acid expression in the tumor microenvironments is linked to immune suppression.

- Targeting the sialic acid-Siglec axis could have beneficial effects in therapy in cancer, allergies and auto immune diseases.

\section{INTRODUCTION}

The human mononuclear phagocyte network consists of monocytes, different subsets of macrophages (MQ) and Dendritic cells (DCs) depending on their origin and tissue micro-environment. In each microenvironment, differentiation is dictated by various components such as stromal cell compartment, presence of immune cells and the diversity 
of chemokines and cytokines present (1). Moreover, mononuclear phagocytes are key instructors for inflammatory or tolerogenic programming of the immune system. The presence of MQ and DCs at multiple sites in the human body, like gut, lung, brain, oral mucosa, lymphnodes, spleen, skin and peripheral blood illustrates their importance in controlling immunity and tolerance (2-5). MQ are plastic cells that can polarize according to the signals they receive and this polarization is mainly described as classical activated M1, alternatively activated M2, or tumor-associated macrophages (TAM). The M1, depicted as pro-inflammatory cells, are induced by stimulating MQ with LPS and/or IFN- $\gamma$ that produce IL-1, TNF- $\alpha$ and nitric oxide. On the other hand, M2 MQ are induced by stimulation with IL-4 and have anti-inflammatory and tissue repair properties, producing Il-10 and TGF- $B(6,7)$. TAMs are found in the microenvironment of tumors, promoting tumor growth by among others release angiogenic factors like VEGF and EGF, attract regulatory $\mathrm{T}$ cells and inhibit effector $\mathrm{T}$ cells by the release of multiple cytokines and chemokines such as IL-10, TGF- $B$, and CCL22 (8). DCs consists also of multiple subsets, were the conventional DCs (cDCs) and plasmacytoid DCs (pDCs) are the main populations in peripheral blood. The cDCs are the main antigen-presenting subset, able to present antigens to and activate antigen specific naïve $\mathrm{CD}^{+}$and $\mathrm{CD} 8^{+} \mathrm{T}$ cells and are able to secrete multiple proinflammatory and anti-inflammatory cytokines like IL12p70 and IL-10, respectively $(9,10)$. pDCs do not prime naïve $\mathrm{T}$ cells, however, there specialized function is the production of type I interferon $(\mathrm{IFN}-\alpha / \beta)$ in response to viruses (11). Different cytokines like IFN- $\alpha$, TNF- $\alpha$ and LPS can polarize cDCs into a more immunogenic state $(12,13)$, while other cytokines like IL-10 and TGF- $\beta$ induce tolerogenic cDCs that express checkpoint ligands like PD-L1 and produce the checkpoint molecule indoleamine 2,3-dioxygenase (IDO). In-vitro treatment of DCs with dexamethasone or vitamin D3 will also result in tolerogenic DCs (14). Functionally the main characteristics of MQ is their phagocytic capacity, while DCs are key in antigen presentation and stimulation of naïve $\mathrm{T}$ cells into antigen-specific effector T cells, however, some of these functions are not $100 \%$ restricted and are also shared between MQ and DCs.

In-vitro, human monocyte-derived DCs (moDCs) and monocyte-derived MQ (moMQ) can be generated from monocytes. Culturing monocytes with GM-CSF and IL-4 gives rise to moDCs, while culturing monocytes with M-CSF or GM-CSF alone creates moMQ $(15,16)$. moDCs and moMQ are often used as model systems for inflammatory DCs and MQ, respectively, as they are easily obtained in large numbers. moDCs are excellent antigen presenters, and able to induce antigen-specific $\mathrm{CD}^{+}{ }^{+}$and $\mathrm{CD} 8^{+} \mathrm{T}$ cells, while culturing with IL-10 or TGF- $\beta$ generates moDC prone to induce tolerance $(4,17-21)$. However, recent studies using mass cytometry as well as single cell RNA sequencing have revealed that moDCs are distinct from human peripheral blood and skin-derived DCs $(2,22)$.

Mononuclear phagocytes have an important function in maintenance of tissue homeostasis and the resolution of inflammation. They express multiple pattern recognition receptors (PRRs), like toll like receptors (TLR) and CLRs to recognize pathogen-associated molecular patterns (PAMPs), damaged self-antigens (DAMPs) or altered glycosylated selfantigens, such as tumor antigens $(3,23)$. The differentiation and maturation status of mononuclear phagocytes alters the expression levels of PRR $(24,25)$. CLRs is a large family of glycan-specific receptors that include, amongst others: DC-SIGN (CD209), Mannose receptor (MR, CD206), DEC-205 (CD205), Dectin-1, Macrophage galactose-type lectin (MGL, CD301) and Langerin (CD207) (26, 27). These CLRs are glycan-binding receptors, recognizing a wide variety of carbohydrate structures, like fucoses and mannoses found on host glycoproteins expressed by cells or pathogens or $\beta$-glucan structures that are only expressed on pathogens such as Aspergillus fumigatus and Saccharomyces cerevisiae (27-29). CLRs play an important role in the antigen uptake for processing and presentation of peptides on MHC class I and II, thereby stimulating antigen-specific T cell responses and $\mathrm{T}$ helper differentiation (27). Some CLRs, like Dectin-1, have the ability to directly modulate the DC or MQ phenotype and cytokine responses, while, other CLRs, like DC-SIGN and MGL are also highly expressed on tolerogenic DC/MQ and modulate TLR signaling through the acetylation of p65 and the induction of IL10 production (30-32).

Next to TLRs and CLRs, mononuclear phagocytes express Sialic acid binding immunoglobulin type lectins (Siglecs), that recognize sialic acids, a family of sugars with a nine-carbon sugar core structure derived from neuraminic acid, with the $\mathrm{N}$ acetylneuraminic acid (Neu5Ac) being the main moiety present in humans (Box 1 and Figure 1). Sialic acids are generally the last sugars added during the glycosylation process, thereby capping a diverse array of glycosylation structures $(44,45)$. Often, the presence of sialic acids functions as a self-associated molecular pattern (SAMP) and thus, Siglecs can serve as sensors for "self" (46). Most Siglecs possess an intracellular immunoreceptor tyrosine-based inhibition motif (ITIM) that induce strong inhibitory signaling when Siglecs bind sialic acids (47). Interestingly, both pathogens and tumor cells use enhanced expression of sialic acids as a mechanism to modify the immune system in their favor, illustrating that the sialic acid-Siglec axis is a key regulator in infection and cancer.

\section{SIGLECS}

The human genome contains 14 different Siglecs, which can be divided into two groups based on their genetic homology among mammalian species. The first group is present in all mammals and consists of Siglec-1 (Sialoadhesin), Siglec-2 (CD22), Siglec4 (MAG), and Siglec-15 (48-50). The second group consists of the CD33-related Siglecs that have evolved rapidly and therefore their repertoire differs between species. The CD33 related Siglecs are Siglec-3 (CD33), $-5,-6,-7,-8,-9,-10,-11,-14$, and -16 (51). Monocytes, moMQ and moDCs have largely the same Siglec profile (Figure 2), namely high expression of Siglec-3,-7,-9, low Siglec-10 expression and upon stimulation with IFN- $\alpha$, also Siglec-1 (52-60) is expressed. In contrast, MQ have primarily expression of Siglec-1,-3,-8,-9,-11,-15, and-16 depending on their differentiation status $(49,52,61,62)$. cDCs express Siglec-3,-7, and -9 , similar to moDCs, but in addition also express low levels of Siglec-2 and Siglec-15 (49, 63-67). pDCs are 
Box 1 | Sialic acid.

Sialic acids are a family of sugars with nine carbons derived from neuraminic acid that are negatively charged. Humans are able to synthetize Neu5Ac (Figure 1A), while other mammals can also synthetize the structure $\mathrm{N}$-glycolylneuraminic acid (Neu5Gc). A deletion in the gene encoding the enzyme CMAH (Cytidine monophosphate- $\mathrm{N}$-acetylneuraminic acid hydroxylase) is the reason why humans cannot produce Neu5Gc (33).
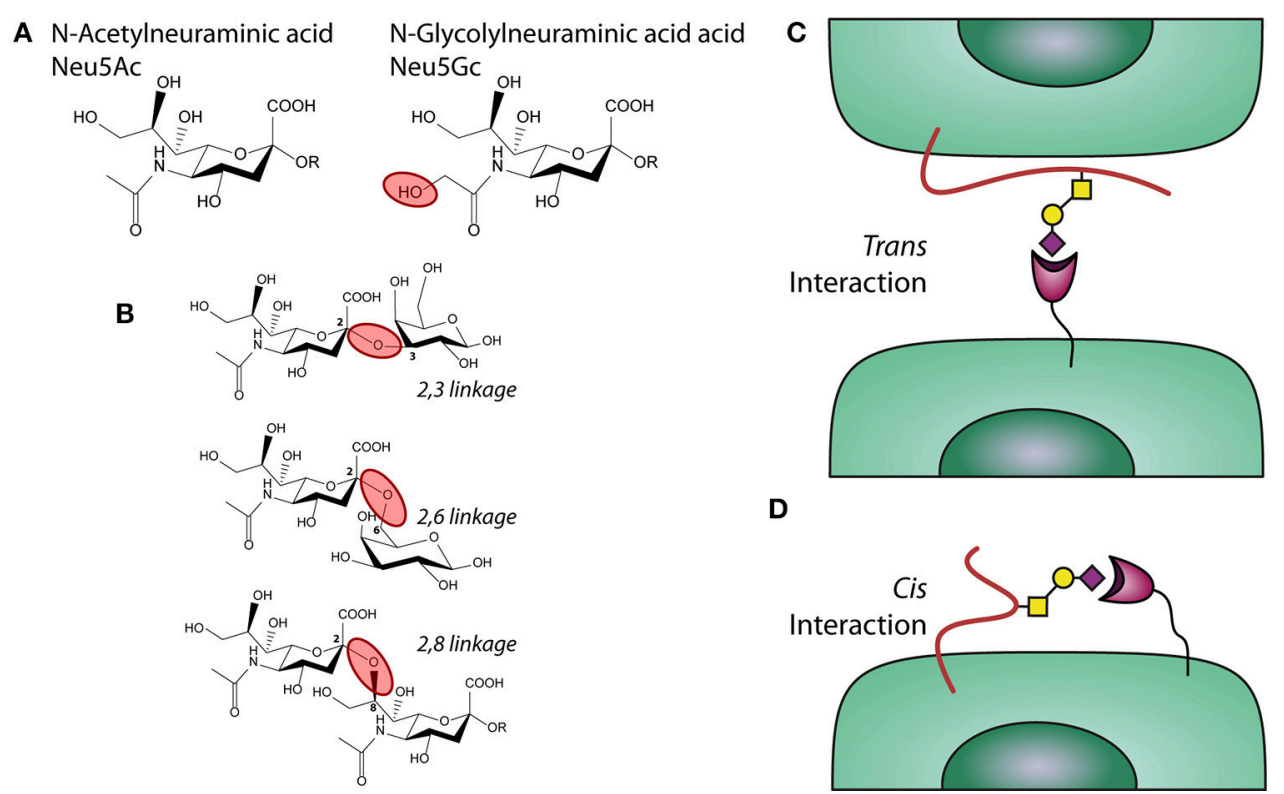

D

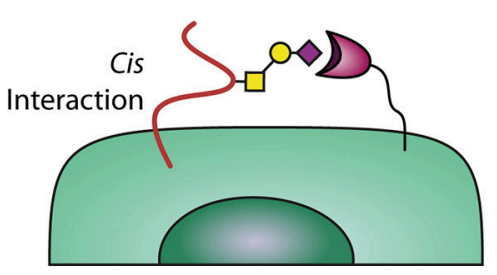

Figure 1 | Sialic acids, linkages, and interactions. (A) chemical structure of sialic acids Neu5Ac and Neu5Gc. (B) $\alpha 2,3 ; \alpha 2,6$, and $\alpha 2,8$ linked sialic acids. (C) Trans and (D) Cis interactions of Siglecs with sialic acids.

\section{Synthesis}

The expression of sialylated glycans is the result of glycosylation related enzymes able to catalyse the addition or removal of a glycan to growing carbohydrate structures. The transfer of sialic acid motifs from an activated donor (CMP-NeuAc, Cytidine 5'-MonoPhospho-N-AcetylNeuraminic acid) to underlying glycans that serve as acceptors, is performed by a group of enzymes called sialyttransferases. Humans express more than 20 different sialyltransferases, each differing in their tissue expression, substrate specificity and linkages produced (34). The synthesis of sialylated structures depends also on the presence of the donor, which is synthetized in the nucleus by the enzyme CMAS (CMP-Neu5Ac synthetase) and subsequently transported into the Golgi via the transporter SLC35A1 (33, 35). Sialic acid blocking glycomimetic: $\mathrm{Ac}_{5} 3 \mathrm{~F}_{\mathrm{ax}} \mathrm{Neu} 5 \mathrm{Ac}$ is a metabolic inhibitor of sialyltransferases that blocks the addition of sialic acids to the glycan backbone (36).

\section{Sialic Acid Linkages}

Sialic acids can be linked to the underlying glycan via different types of linkages, which affects their recognition by glycan-binding receptors, such as Siglecs. These linkages mainly have an alpha configuration and are defined by which carbon in the acceptor glycan is connected to the anomeric carbon in the Neu5Ac (carbon 2). When sialic acid is transferred to a different glycan, the bond can involve the carbon 3 or 6 in the acceptor rising to $\alpha 2,3$ or a $\alpha 2,6$ linkages, respectively, (33, 35) (Figure 2B). In poly-sialic acid structures, one Neu5Ac is added to a strain of sialic acids in an $\alpha 2,8$ linkage. The different Sialic acid linkages are depicted in the complementary figure to this box.

\section{Trans/Cis Interaction}

Siglecs can interact with sialic acid on a different cell or protein/particulate (trans interaction) or with sialic acids present on the same cell that expresses the receptor (cis interaction), as depicted in the figure complementary with this box. An illustration of a trans interaction is $\alpha 2,3$ linked sialic acids expressed by lung epithelium under inflammatory conditions and Siglecs present on neutrophils $(37,38)$ (Figure 1C). An example of a cis interaction is $\alpha 2,3$ linked sialic acid present on the cell surface of moDCs, which bind to a Siglecs present on the same moDCs (39) (Figure 1D).

\section{Degradation}

Specific glycosidases, called neuraminidases or sialidases, can hydrolyse the sialic acid from oligosaccharides. Present mainly in intracellular vesicles, these enzymes can be secreted, thereby changing the profile of sialylated structures present on the cell membrane. Their expression is dysregulated in many different types of cancer.

\section{Sialic Acid Immune Modulation}

Sialic acids can modulate the immune system in diverse ways through Siglecs, influence on antibody mediated clearance of pathogens and through complement. Sialylation of the antibody immunoglobulin A ( $\lg A$ ) interferes with the cell surface attachment of influenza A and mediates anti-viral activity of IgA (40). Sialic acids can also bind to complement regulator factor $\mathrm{H}$ and by this negatively regulate the complement alternative pathway (41-43). 


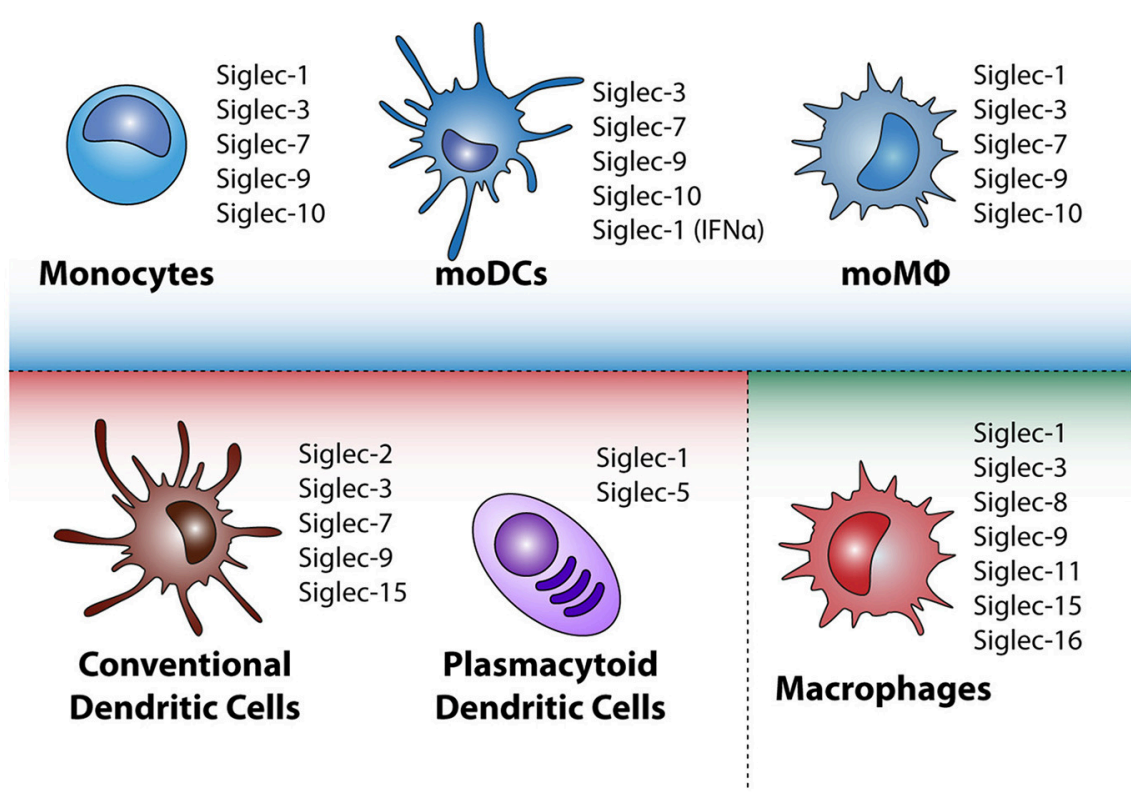

FIGURE 2 | Siglec expression by different mononuclear phagocytes in steady state. Depicted in the blue square are monocytes and in-vitro cultured monocyte-derived dendritic cells (moDC) and monocyte-derived macrophages (moMQ). In the red square the conventional dendritic cells and plasmacytoid dendritic cells that appear in peripheral blood are highlighted, whereas in the green square tissue resident macrophages (MQ) are depicted. Depending on microenvironmental triggers the immunogenic or tolerogenic status of the mononuclear phagocyte can change, leading to altered Siglec expression.

different in their expression of Siglecs, as they express Siglec-1 and Siglec-5 $(54,68)$. The presence of the Siglecs on mononuclear phagocytes is based on their steady state situation, however, microenvironmental triggers that change the maturation status of the cell, may influence the loss or gain of the expression of Siglecs. Downregulation of Siglecs-7 and Siglec-9 expression on moDCs is observed after stimulating moDCs for $48 \mathrm{~h}$ with LPS, however, on moMQ Siglec expression is not changed upon LPS triggering (54). Clearly, further research on the regulation of Siglec expression during cellular maturation is needed. Siglecs are also present on other immune cells [nicely reviewed by MacAuley et al. (69)], such as B cells, basophils, neutrophils, and NK cells, with different expression patterns for every cell subset.

Sialic acids, the ligands for Siglecs receptors, are widely expressed as they are exposed on the outermost end of glycosylated structures of glycoproteins expressed on immune and other cells in the body, secreted glycoproteins in tissues and blood and on extracellular matrix in tissues $(70,71)$. It is the glycosylation machinery of the cells that determines the type of sialic acids to be added on the carbohydrate backbone to be expressed by the glycoprotein (Box 1, Figure 1). A Siglecexpressing immune cell can bind to sialic acids present on another cell or secreted glycoprotein and this is called a trans interaction (72) (Figure 1). Siglec receptors can also bind sialic acids exposed on the same cell, called a cis interaction. Moreover, Siglec receptors have different binding affinities for different linkage and modifications of sialic acids (see Box $\mathbf{1}$ for more information about sialic acid). Most Siglecs have a preference for a particular sialic acid linkage, being either $\alpha 2,3, \alpha 2,6$, or $\alpha 2,8$-linked sialic acid but Siglecs may also show redundant specificity toward more linkages $(52,58)$.

\section{IMMUNE MODULATION THROUGH SIGLEC SIGNALING}

The immune modulatory effect induced upon sialic acid binding to Siglec is regulated through downstream signaling pathways. Siglec-5 till Siglec-11, are the so-called inhibitory Siglecs, carrying ITIM and/or ITIM like motifs in their cytoplasmic domains, which can be phosphorylated by the Src family, thereby creating a binding site for the tyrosine phosphatases SHP-1 and SHP2 (Figure 3A). Upon binding of SHP-1/2, de-phosphorylation of downstream targets can be achieved and ubiquitination, internalization, and phosphorylation of the receptor can be regulated $(73,74)$. The Src-mediated phosphorylation of ITIMs in Siglec-3 and possible also other ITIM-containing Siglecs can also lead to the binding of Cbl, a RING finger-containing E3 ligase, and suppressor of cytokine signaling 3 (SOCS3), resulting in the ubiquitination and protosomal degradation of Siglec-3. The same process also regulates the internalization and surface abundance of Siglec-3. SOCS proteins are upregulated by cytokines during inflammatory responses, leading to the loss of Siglec-3 and thereby higher proliferation of myeloid cells $(75,76)$ (Figure 3A). Signaling of different Siglecs through the binding of sialic acids or crosslinking via antibodies can lead to both an inflammatory or tolerogenic state in distinct mononuclear phagocytes. Antibodies against Siglec-3 and -7 inhibit the proliferation of myeloid cells (77) while monocytes 

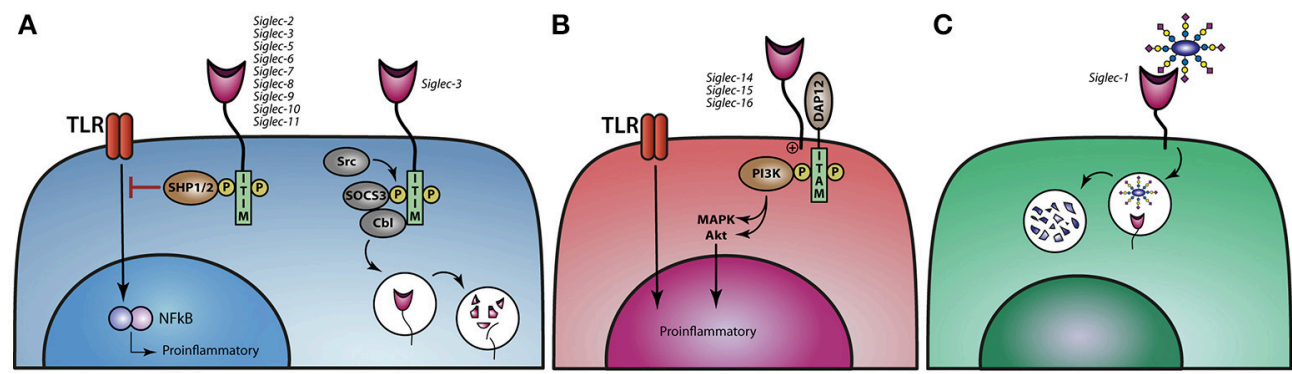

FIGURE 3 | Siglec signaling and the immune modulatory effect on TLR signaling. (A) Siglec-2, -3 , and-5 till-11 modulate TLR signaling upon binding of sialic acids and thereby dampen proinflammatory responses. Ligand binding to Siglec-3 leads to phosphorylation of the ITIM motif and reveals a binding site for SOCS3 and CbI, causing proteasomal degradation of Siglec-3 and SOCS3. (B) Activating Siglecs-14,-15, and-16 can associate with DAP12, resulting in the activation of the MAPK and AKT pathways, thereby stimulating a proinflammatory response. (C) Siglec-1 can internalize upon binding of its ligand and thereby present antigens to dendritic cells or B cell to initiate an immune response.

treated with Siglec-3 antibodies show increased production of the pro-inflammatory cytokines IL- $1 \beta$, TNF- $\alpha$, and IL-8 (78). These findings illustrate that crosslinking of Siglec-3 expressed on different myeloid cells induces opposite functional outcomes. Moreover, crosslinking Siglec-3 on monocytes via antibodies signals a pro-inflammatory effect, while cis binding of sialic acids to Siglec- 3 represses IL- $1 \beta$ production by monocytes (78).

In contrast, Siglec-4 and Siglec-14 till Siglec-16 do not have an ITIM or ITIM like motif, but instead signal through the association of DNAX activation protein (DAP)12 and are therefore called activating Siglecs. DAP12 associates with these activating Siglecs through a positively charged lysine residue in the transmembrane domains and contain a cytosolic immunoreceptor tyrosine-based activation motifs (ITAM), which can recruit PI3K (Figure 3B) (49, 62). Furthermore, Siglec-14 can promote an inflammatory response by activating the MAPK pathway (46). The activating Siglecs most likely developed under evolutionary pressure, when pathogens adapted using the inhibitory Siglecs to circumvent the immune system, allowing sialic acids to also activate the immune system. There are a couple of paired Siglecs, consisting of an inhibitory and an activating Siglec, like Siglec-5 and Siglec-14 as well as Siglec-11 and Siglec-16. Polymorphisms in Siglec-5/14 have been described, whereby the Siglec-14 gene is deleted and the Siglec-5 gene is present under the Siglec-14 promotor. When monocytes from these individuals are challenged with LPS or with group B streptococcus (GBS) they produce less TNF- $\alpha$ than individuals that have normal Siglec-5 and Siglec-14 expression on their monocytes, indicating that Siglec-14 is tipping the balance toward the pro-inflammatory site when cells are confronted by pathogens $(46,61,62)$.

Siglec-1 is a non-signaling Sigelc, that internalizes upon ligand binding (Figure 3C). Den Haan et al. showed in mice that antigen coupled to Siglec- 1 antibodies targets Siglec-1 expressing marginal zone macrophages that transfer antigen to $\mathrm{CD}^{+} \mathrm{DC}$ favoring effective antigen specific $\mathrm{T}$ cells to eradicate tumor growth $(79,80)$. Furthermore, it has been shown that Siglec$1^{+}$MQ promote germinal center B cell responses upon Siglec-1 antibody targeting (81).
Siglecs can also exert their immune modulatory effects by altering TLR signaling. LPS stimulation of TLR4 induces CCR7 upregulation of moMQ which is inhibited by anti-Siglec-9 antibodies or knock down of expression of Siglec-9 (53, 82). G. Chen and colleagues revealed that TLR4 forms a complex with Siglec E (mouse homologue for human Siglec-7 and Siglec-9) in murine DCs and macrophages (83). This cis interaction between Siglec-E and TLR4 is likely mediated by sialic acids present on the TLR (83). The TLR-Siglec-E interaction, is abrogated by NEU1 (a lysosomal sialidase that cleaves sialic acids from their glycoprotein backbone), which is translocated to the cell membrane upon LPS stimulation.

moDCs treated with the $\mathrm{Ac}_{5} 3 \mathrm{~F}_{\mathrm{ax}} \mathrm{Neu} 5 \mathrm{Ac}$ (Box 1), showed reduced sialic acid expression and a lower threshold of TLR activation, leading to increased sensitivity and response to poly I:C (TLR 3 agonist) and LPS, as reflected by the induction of moDC maturation and cytokine production by moDCs (55). Furthermore, it has been reported that sialic acid removal from moDCs uncovers Siglecs from their cis binding sialic acid ligands and increases expression of the maturation markers CD80 and CD86 and the secretion of IL-12 (84). Also, the cross presentation of melanoma antigens gp100 by DCs to antigen-specific $\mathrm{CD}^{+} \mathrm{T}$ cells was increased upon removal of sialic acid on moDC, illustrating that the presence of sialic acid constraints, that occupy Siglecs in cis, inhibits the effectiveness of moDC to induce immunity (84). Alternatively, targeting Siglecs with sialic acids or sialic acid mimetics in trans can modulate TLR signaling leading to a more tolerogenic DC phenotype. This illustrates that interference in the sialic acidSiglec axis is central in the balance between immunity and tolerance.

\section{SIALIC ACIDS USED BY PATHOGENS TO MODULATE IMMUNITY}

The co-evolution of the immune system and pathogens has led to the acquisition of several strategies for pathogens to evade the immune system, which also includes the expression 
of sialylated glycans to induce tolerance. One of the most notable examples is Trypanosoma cruzi, a protist parasite responsible for Chagas disease. During its infective stage in vertebrates, called trypomastigote, T. cruzi expresses a unique enzyme called trans-sialidase that catalyses the reversible transference of sialic acid from host glycoconjugates to glycan structures on the surface of the parasite. By doing this, T. cruzi uses host glycans to mask its own antigens and to modulate anti-parasitic responses (85). Parasitic sialylated glycans can interact with Siglec-E [homolog of human Siglec 7 and 9, Siglec comparison between Mammalians was recently reviewed by Bornhöfft et al. (86)] in murine dendritic cells to suppress the production of the pro-inflammatory cytokine IL-12 (87). Moreover, the addition of sialic acid to the surface of the parasite results in a negatively charged coat that inhibits complement-mediated killing. Furthermore, thanks to the trans-sialidase activity, T. cruzi is also able to alter the sialylation status of $\mathrm{CD}^{+} \mathrm{T}$ cells, dampening their capacity to induce an effective anti-parasitic immune response (88).

Interestingly, several pathogenic bacteria also use the sialic acid-Siglec axis to dampen the immune system in favor of their survival. Despite the fact that sialic acids are mainly restricted to vertebrates, some bacteria have acquired the ability to take sialic acids or sialylated structures from the host, to synthetize "mimic" structures or even perform de novo synthesis of sialic acids, giving them a survival advantage. For example, Siglec- 5 and -9 on neutrophils can be triggered by glycoconjugates present in Pseudomonas aeruginosa or Group $B$ streptococcus (GBS) serotypes Ia and III, thereby inhibiting their ability to respond to the bacteria. Moreover, sialylated glycans present in $G B S$ are able to inhibit the complement system, by reducing deposition of $\mathrm{C} 3 \mathrm{~b}$ on their surface and, therefore, the generation of $\mathrm{C} 5 \mathrm{a}$ and the membrane attack complex (89-91).

The presence of sialic acids in envelope glycoproteins of viruses also contributes to enhanced infection of the host. This is the case for the Human immunodeficiency virus (HIV) and the Porcine reproductive and respiratory syndrome virus (PRRSV), which can bind to Siglec-1 to promote trans infection (9294). Nevertheless, Siglec-1 ligands on GBS surface interact with Siglec-1 on marginal zone macrophages for the subsequent generation of anti-GBS immune responses (95).

Influenza $A$ virus recognizes $\alpha 2,3$ and $\alpha 2,6$ linked sialic acids with its hemagglutinin (HA) glycoproteins to infect host cells. On the other hand, influenza A virus carries the neuraminidase (NA) glycoprotein that can cleave off sialic acids from cellular and viral glycoproteins that are expressed in infected cells and assembled in virions, to reduce HA causing aggregation of the virions to the cell surface. The HA and NA proteins are in perfect balance to warrant infection and to abolish detection by the immune system (96). Another example is the nontypeable Haemophilus influenzae (NTHi), which is also able to take up sialic acids through a tripartite ATP-independent periplasmic (TRAP) transporter. Incorporation of the sialic acids in the NTHi membrane protects it from serum-mediated killing (97).
Sialic acids are used by different pathogens to infect host cells and dampen the immune response. Knowledge on this mechanism can be exploited to design new therapeutic strategies in cancer or auto-immune diseases and asthma.

\section{SIALIC ACID-SIGLEC AXIS IN CANCER}

Aberrant glycosylation of multiple cancers and its influence on cancer progression and metastasis are well-known. Increased sialylation, $\alpha 2,3 ; \alpha 2,6$, and $\alpha 2,8$ linked sialic acids, has been demonstrated in multiple tumor tissues like renal cell carcinoma, prostate cancer, colon cancer, breast cancer, head and neck squamous cell carcinoma and oral cancer (98-101). This aberrant sialylation can also be detected in serum serving as potential biomarkers for cancer detection, progression and treatment responses (99, 101-103) (Figure 4).

In a mouse model for melanoma, hyper sialylation of B16 melanoma cells leads to increased tumor growth, associated with an enhanced $\mathrm{T}$ regulatory/T effector balance and reduced NK cell activity within the tumor and secondary lymphoid organs (110). DCs that interacted and sampled sialylated antigens via Siglec-E (murine homologue of human Siglec-7 and Siglec9) induced regulatory $T$ cells and inhibited effector $T$ cell function in-vivo. These findings revealed that tumor sialylation impedes $\mathrm{T}$ cell-mediated anti-tumor immune responses, while promoting tumor-associated regulatory $\mathrm{T}$ cells (110). Blocking the inhibitory effects of sialic acids with a sialic acid blocking glycomimetic (Box 1) in a B16-OVA mouse model revealed reduced tumor growth, enhanced tumor killing by ovalbumin specific $\mathrm{CD} 8^{+} \mathrm{T}$ cells and inhibition of metastasis $(106,107)$ (Figure 4C).

In breast cancer a specific glycoform of transmembrane mucin 1, MUC1-T is sialylated, creating MUC1-sT $(111,112)$. The MUC1-sT can interact with Siglec-9 on monocytes and thereby induce secretion of IL-6, M-CSF and chemokines associated with tumor progression. Binding of MUC1-sT to Siglec9 on macrophages induces a tumor-associated macrophage (TAM) phenotype, that inhibits $\mathrm{CD}^{+} \mathrm{T}$ cell proliferation and results in the upregulation of IDO, CD163 and PDL1 in-vivo $(113,114)$. Another specific mucin glycoform, called MUC2-sT, has been shown to increase apoptosis of immature moDCs (115). Together, this points toward a broad immunological suppression by tumor-produced sialylated mucins.

Antibodies against Siglecs are explored for the treatment of different cancer types. For Acute Lymphoblastic Lymphoma (ALL) the FDA approved Inotuzumab Ozogamicin (Besponsa ${ }^{\circledR}$ ), a monoclonal antibody against Siglec-2 coupled to the toxic agent calicheamicin is used. This antibody targets Siglec-2 positive Blymphoblasts and causes cell death of these cells through the toxic agent (Figure 4A). Trials with this antibody revealed that an enhanced number of patients reached complete remission and had an increased overall progression free survival. However, serious adverse effects were seen like myeloid suppression (104), which could be due to the presence of Siglec-2 on DC subsets. Another Siglec that is targeted for the treatment 


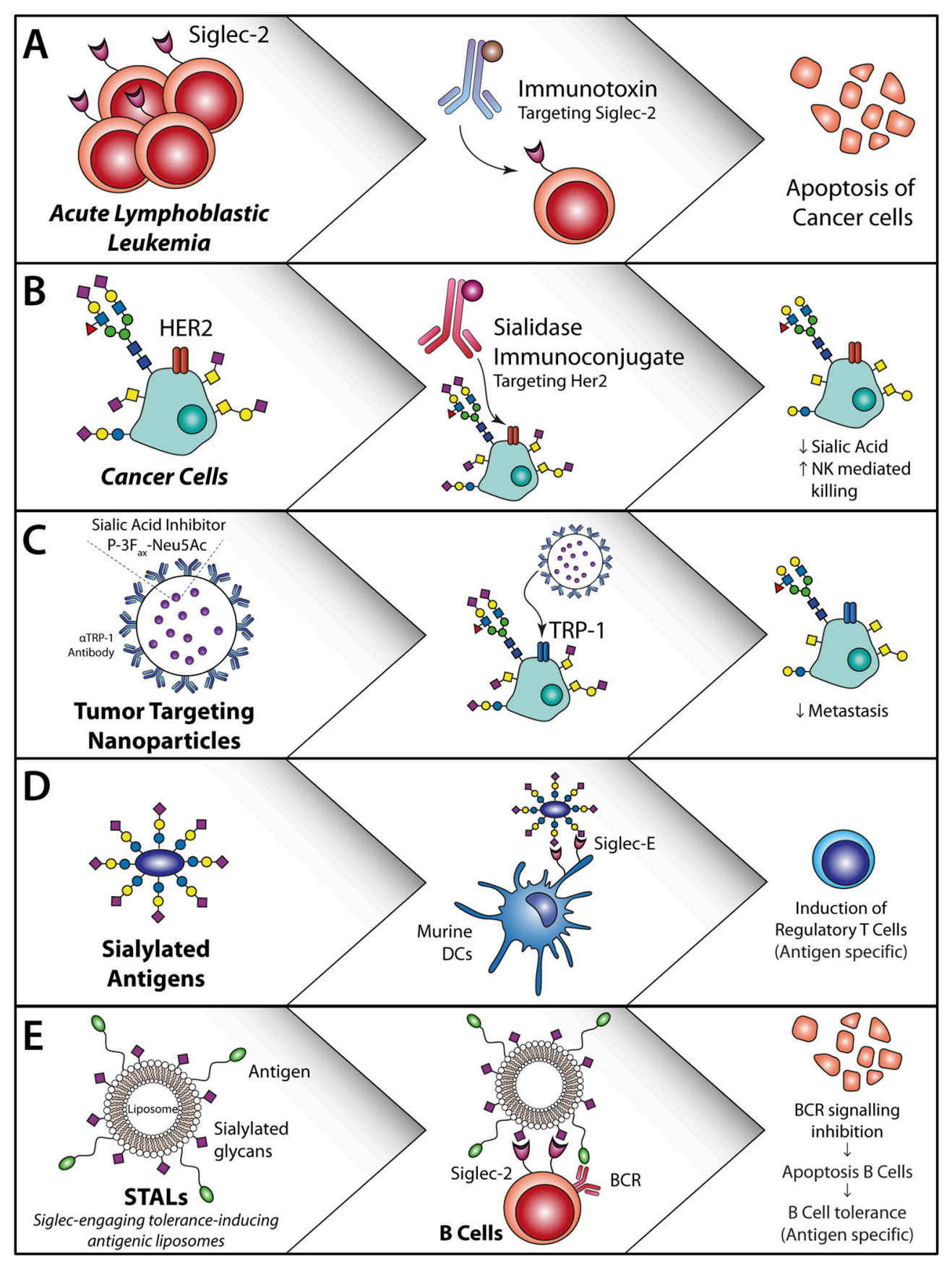

FIGURE 4 | Sialic acid-Siglec axis usage for the treatment of cancer or allergies and auto-immune diseases. (A) Siglec-2 antibodies coupled to an immunotoxin induce apoptosis of Siglec-2-expressing acute lymphoblastic leukemia cells (104). (B) HER2 targeting with a sialidase coupled to the HER2 antibody or locally applied non-targeted sialidases/synthesis inhibitors. This decreases sialic acid expression, reduce T reg induction and induced T cell activation and initiates NK cell killing (105). (C) Sialic acid inhibitor P-3Fax-Neu5Ac inclusion in nanoparticles targeted to tumor cells inhibits the sialic acid expression on the tumor cells, thereby decreasing metastasis and increasing tumor cell killing $(106,107)$. (D) Sialylated antigens target DC to remove regulatory T cells (108). (E) Antigen-specific B cell apoptosis induction by STALs targeting Siglec-2 in combination with an antigen that inhibits B cell receptor signaling on B cells (109).

of acute myeloid leukemia (AML), is Siglec-3, using Siglec3 antibody coupled to calicheamicin $(116,117)$. Hereby, the myeloid blasts that express Siglec-3 are targeted and this improved outcome in patients with relapsing disease as well as in elderly patients that were not eligible for extensive chemotherapy (116). Similar to the Siglec-2 antibody treatments, the Siglec3 antibodies caused extensive adverse effects, probably due to the wide spread expression of Siglec-3 on (healthy) myeloid 
subsets. Therefore, it is of great imporatnce to have a complete and accurate overview of Siglec expression on immune cells. Other strategies to target Siglec-3 in AML include the use of CAR-T cells. Siglec-3 targeting CAR T-cells have shown to induce $\mathrm{CD}^{+} \mathrm{T}$ cell degranulation against primary $\mathrm{AML}$ and AML cell lines in-vitro $(118,119)$. Although different CAR-T cells are already tested in the clinic for lymphoid leukemia (120), it is questionable whether Siglec3 targeting CAR$\mathrm{T}$ cells have similar severe side effects as observed with Siglec-3 antibodies.

Instead of targeting the Siglecs using antibodies, modifying the phosphorylation status of Siglec-3 and Siglec-9, in particular dephosphorylation of the receptos, has shown to lead to increased immunity of moDCs, when treated with Dasatinib a SRC tryrosine kinase inhibitor that dephosphorylates Siglec-3 and Siglec-9 (121). Also, leukemia (BCR-ABL ${ }^{+}$AML) patients treated with Dasatinib, had a stronger $\mathrm{CD}^{+} \mathrm{T}$ cell and $\mathrm{NK}$ cell response associated with long lasting remission (122). Another strategy to increase anti-tumor immunity through Siglecs has been developed by Xiao et al., where they target HER2 with a monoclonal antibody fused to a sialidase (105) (Figure 4B). This sialidase specifically cuts off the sialic acid ligands that are bound by Siglec-7 and Siglec- 9 and thereby increase NK activity. In vitro these HER2 targeting antibodies fused to a sialidase, increased the NK cell mediated killing of HER2 positive tumor cells (105). As most breast cancer patients are HER2 positive, targeting of HER2 with this sialidase fused antibody could be an effective treatment strategy.

Most strategies that interfere with the sialic acids-Siglec Axis are developed for leukemic cells as they have high expression of Siglec-2 or Siglec-3 and are therefore easily targetable. Other cancer type treatments could also benefit from targeting Siglecs, blocking of Siglecs could abrogate the inhibitory effects on mononuclear phagocytes and lead to better migration and maturation of these cells, which subsequently stimulates tumorspecific $\mathrm{T}$ cell responses. Moreover, local removal of tumorassociated sialic acid may temporarily de-tolarize the tumor microenvironment and trigger immune activation at the tumor site. A combination with checkpoint inhibitors would than favor improved tumor eradication.

\section{SIALIC ACID-SIGLEC AXIS TO INDUCE TOLERANCE FOR ALLERGIES AND AUTO-IMMUNE DISEASES}

While in cancer it is important to induce immunity, in allergies and auto-immune diseases, an overactive immune system needs to be restored by inducing tolerance. Exploring the potential of the Sialic acid-Siglec Axis is an alternative to induce tolerance in an antigen specific manner. Because immune inhibitory Siglecs are found on mononuclear phagocytes, strategies can be designed aimed to actively induce tolerance via targeting inhibitory Siglecs on mononuclear phagocytes.

Modification of antigens such as OVA or MOG peptides with $\alpha 2,3$ or $\alpha 2,6$ sialyl-lactose has shown to increase targeting of these antigens to Siglec E, the human Siglec 7 and Siglec9 homologue, and alter DC function in mice. Both in-vitro and in-vivo experiments demonstrated that sialic acid modified antigens induced antigen specific $\mathrm{T}$ reg induction and inhibition of inflammatory effector cells when activated with LPS (108) (Figure 4D).

Also, Siglec-engaging tolerance-inducing antigenic liposomes (STALs) are employed, in which sialic acid decorated nanoparticles, or sialo-glycoproteins or Siglec antibody targeting are used for Siglec targeting to induce tolerance. STALs with the peanut allergen Ara h2 (Ah2) and a high affinity Siglec-2 ligand (modified $\alpha 2,6$ linked sialic acid) incorporated in the outer membrane have shown high binding affinity to the B cell receptor and Siglec-2 simultaneously and to prevent peanut allergy against the Ah2 allergen in mice (109) (Figure 4E). This is acclaimed to the forced interaction between the $\mathrm{B}$ cell receptor and Siglec-2, thereby inducing apoptosis of autoreactive B cells. Pang et al. used the same STALs and incorporated rapamycin in the STALs and thereby enhanced the tolerogenic capacity in mice, which was the result of increased phagocytosis of these STALs by macrophages and DCs (123).

Sialic acid mimetics, such as the modified sialic acid coupled to liposomes discussed above, comprise of natural sialic acids as a backbone and are modified at certain positions in the sialic acid structures to develop high affinity ligands for Siglecs (124126). Addition of hydrophobic groups at the $C 2$ and $C 9$ of $\alpha 2,6$ sialic acids results in a high affinity Siglec-2 ligands, which outcompeting the cis interaction between the Siglec and its ligand. As a result better binding, endoyctosis, and eventually apoptosis of targeted B cells is acquired $(126,127)$.

Nanoparticles decorated with $\alpha 2,8$ linked sialic acids were developed to target murine Siglec-E (homologue of human Siglec-7 and Siglec-9) on macrophages. This approach limited the pro-inflammatory cytokines production by LPS-treated MQ in-vitro. Subsequently, these nanoparticles were able to limit the inflammation and increase levels of IL-10 in serum in a mouse model for LPS-induced systemic inflammation. Similar results were seen with human moMQ, resulting in an antiinflammatory cytokine profile. In an ex-vivo human lung perfusion model the nanoparticles coated with $\alpha 2,8$ linked sialic acids reduced pulmonary oedema after LPS-induced injury (128).

Several studies have shown the importance of Siglec-sialic axes in auto-immune disease and allergy due to expression of Siglecs on other immune cells such as eosinophils and B-cells. Asthma is an eosinophil, expressing Siglec-8, mediated disease and it has been shown that polymorphisms in the SIGLEC8 gene are linked to the development of asthma $(38,129)$. Antibodies against Siglec- 8 or the mouse homolog Siglec-F induce caspase and ROS dependent apoptosis of eosinophils $(130,131)$. Autoantibodies against Siglec- 8 have been found in intravenous immunoglobulin preparations that are used in various chronic inflammatory disorders, although some cytotoxic effects are known (132). For asthma it would be beneficial to have specific Siglec- 8 agonists to induce neutrophil apoptosis without the risk of side effects observed with intravenous immunoglobulin injections. Another example is the anti-Siglec-2 antibody (Epratuzumab) that has 
already been tested in seven clinical trials for the autoimmune disease systemic Lupus erythematosus (SLE). Although initial trials showed promising effects with reduced peripheral B cell numbers, the overall effect was not better than standard care for SLE (reviewed by D Geh) (133).

Most of these strategies are to date only tested in in-vitro or ex-vivo experiments and should be tested in in-vivo and clinical trials as they have great potential for future applications in the treatment of allergies and auto-immune diseases. It is also important to elucidate the Siglec expression on different human immune cell subsets in order to identify the potential risks on side-effects by targeting multiple Siglecs with one ligand.

\section{CONCLUDING REMARKS}

The last decade researchers identified the enormous potential of the sialic acid-Siglec axis to induce wanted or unwanted immune tolerance in cancer, allergies or auto-immune diseases. Both Siglec targeting antibodies, sialic acid mimetics, or glycan modifying agents can be used to interfere in this process and open new area's in the design of novel therapies for cancer, allergy and auto-immune diseases.

Still several questions need to be answered related to a better understanding of the biology of the Siglec-sialic acid axis. Those relate to the signaling capacity that sialic acid impose on immune cells to modify its function toward tolerance induction or activation of immunity. Interesting research topics to be addressed are: How do the various Siglecs expressed on one cell communicate with each other What is the exact specificity of these receptors for sialic-acids? Does multivalency of sialic acids or Siglec receptors matter? Other intriguing questions to be solved are: Do we need to inhibit only one Siglec receptor or more Siglec receptors simultaneously on one cell to alter function? What is the relation to cis and trans interaction on Siglecsialic acid interactions? How important is the protein or lipid backbone on which the sialic acid is exposed? To answer these questions an urgent need for Siglec specific targeting molecules is needed, which can be sialic acid mimetics or Siglec specific antibodies.

As the Siglec-sialic axis plays a crucial role in tissue homeostasis and the resolution of inflammation, more studies are necessary to understand their involvement in these biomedical

\section{REFERENCES}

1. Schlitzer A, McGovern N, Ginhoux F. Dendritic cells and monocytederived cells: two complementary and integrated functional systems. Semin Cell Dev Biol. (2015) 41:9-22. doi: 10.1016/j.semcdb.2015. 03.011

2. Alcántara-Hernández M, Leylek R, Wagar LE, Engleman EG, Keler T, Marinkovich MP, et al. High-dimensional phenotypic mapping of human dendritic cells reveals interindividual variation and tissue specialization. Immunity (2017) 47:1037-50.e6. doi: 10.1016/j.immuni.2017.11.001

3. Ginhoux F, Jung S. Monocytes and macrophages: developmental pathways and tissue homeostasis. Nat Rev Immunol. (2014) 14:392-404. doi: $10.1038 /$ nri3671 processes. A better understanding of its role in the resolution of inflammation is crucial for its application in the treatment of auto-immune diseases and allergies.

Moreover, both pathogens and tumors use the Siglecsialic acid axis in their own benefit. It is therefore of vital importance to design new methods to modify glycosylation at site of infection or tumor location. Several studies already touch upon the investigation of targeting specific sialidases to the tumor micro-environment to remove the sialic acid content involved in the induction of tolerance in the tumor microenvironment. To unleash the sialic acid imposed tolerance in the local tumor microenvironment may be combined with other immune checkpoint inhibitors to stimulate tumor immunity in a multilevel manner. Alternatively, presence of sialic acid signatures in the tumor microenvironment may serve as new biomarkers to define immune tolerizing signatures in individual tumors and response therapy prediction (99).

Future studies are of great importance to unveil the complex Siglec-sialic acid axis and will warrant new discoveries in clinical application strategies in cancer, allergy and auto-immune diseases.

\section{AUTHOR CONTRIBUTIONS}

JL was involved in the writing, reading of literature, design and discussion of the figures. ER was involved in writing, critical reading of the manuscript and designing the figures. YvK was involved in the overall supervision of the review and editing of the manuscript.

\section{FUNDING}

This study was supported by ERC/Advanced/ERC339977/ Glycotreat (JL and YvK) and the European Training Network IMMUNOSHAPE (ER).

\section{ACKNOWLEDGMENTS}

We gratefully thank Sandra J. van Vliet and Juan J. García-Vallejo, Amsterdam, UMC, Vrije University Amsterdam (Amsterdam, The Netherlands) for critical reading and fruitful discussions.
4. Haniffa M, Bigley V, Collin M. Human mononuclear phagocyte system reunited. Semin Cell Dev Biol. (2015) 41:59-69. doi: 10.1016/j.semcdb.2015.05.004

5. Kosten IJ, Van De Ven R, Thon M, Gibbs S, De Gruijl TD. Comparative phenotypic and functional analysis of migratory dendritic cell subsets from human oral mucosa and skin. PLoS ONE (2017) 12:1-15. doi: 10.1371/journal.pone.0180333

6. Nahrendorf M, Swirski FK. Abandoning M1/M2 for a network model of macrophage function. Circ Res. (2016) 119:414-7. doi: 10.1161/CIRCRESAHA.116.309194

7. Murray PJ, Allen JE, Biswas SK, Fisher EA, Gilroy DW, Goerdt S, et al. Macrophage activation and polarization: nomenclature and experimental guidelines. Immunity (2014) 41:14-20. doi: 10.1016/j.immuni.2014.06.008 
8. Liu Y, Cao X. The origin and function of tumor-associated macrophages. Cell Mol Immunol. (2015) 12:1-4. doi: 10.1038/cmi.2014.83

9. Jongbloed SL, Kassianos AJ, McDonald KJ, Clark GJ, Ju X, Angel CE, et al. Human CD141+ (BDCA-3) + dendritic cells (DCs) represent a unique myeloid DC subset that cross-presents necrotic cell antigens. J Exp Med. (2010) 207:1247-60. doi: 10.1084/jem.20092140

10. Collin M, McGovern N, Haniffa M. Human dendritic cell subsets. Immunology (2013) 140:22-30. doi: 10.1111/imm.12117

11. Liu Y-J. IPC: professional type 1 interferon-producing cells and plasmacytoid dendritic cell precursors. Annu Rev Immunol. (2005) 23:275-306. doi: 10.1146/annurev.immunol.23.021704.115633

12. Li MO, Flavell RA. Contextual regulation of inflammation: a duet by transforming growth factor- $\beta$ and interleukin-10. Immunity (2008) 28:46876. doi: 10.1016/j.immuni.2008.03.003

13. Schülke S. Induction of interleukin-10 producing dendritic cells as a tool to suppress allergen-specific T helper 2 responses. Front Immunol. (2018) 9:455. doi: 10.3389/fimmu.2018.00455

14. Yoo S, Ha SJ. Generation of tolerogenic dendritic cells and their therapeutic applications. Immune Netw. (2016) 16:52-60. doi: 10.4110/in.2016.16.1.52

15. Romani N. Proliferating dendritic cell progenitors in human blood. J Exp Med. (1994) 180:83-93. doi: 10.1084/jem.180.1.83

16. Ohradanova-Repic A, Machacek C, Fischer MB, Stockinger H. Differentiation of human monocytes and derived subsets of macrophages and dendritic cells by the HLDA10 monoclonal antibody panel. Clin Transl Immunol. (2016) 5:e55. doi: 10.1038/cti.2015.39

17. Cravens PD, Hayashida K, Davis LS, Nanki T, Lipsky PE. Human peripheral blood dendritic cells and monocyte subsets display similar chemokine receptor expression profiles with differential migratory responses. Scand J Immunol. (2007) 65:514-24. doi: 10.1111/j.1365-3083.2007.01933.x

18. Ruben JM, Bontkes HJ, Westers TM, Hooijberg E, Ossenkoppele GJ, de Gruijl TD, et al. Differential capacity of human interleukin-4 and interferon$\alpha$ monocyte-derived dendritic cells for cross-presentation of free versus cell-associated antigen. Cancer Immunol Immunother. (2015) 64:1419-27. doi: 10.1007/s00262-015-1741-1

19. Tang-Huau TL, Gueguen P, Goudot C, Durand M, Bohec M, Baulande $\mathrm{S}$, et al. Human in vivo-generated monocyte-derived dendritic cells and macrophages cross-present antigens through a vacuolar pathway. Nat Commun. (2018) 9:2570. doi: 10.1038/s41467-018-04985-0

20. Faure F, Jouve M, Lebhar-Peguillet I, Sadaka C, Sepulveda F, Lantz O, et al. Blood monocytes sample MelanA/MART1 antigen for long-lasting crosspresentation to CD8+ $\mathrm{T}$ cells after differentiation into dendritic cells. Int J Cancer (2018) 142:133-44. doi: 10.1002/ijc.31037

21. Schultze JL, Aschenbrenner AC. Systems immunology allows a new view on human dendritic cells. Semin Cell Dev Biol. (2018). doi: 10.1016/j.semcdb.2018.02.017. [Epub ahead of print].

22. Balan S, Ollion V, Colletti N, Chelbi R, Montanana-Sanchis F, Liu H, et al. Human XCR1 + dendritic cells derived in vitro from CD34+ progenitors closely resemble blood dendritic cells, including their adjuvant responsiveness, contrary to monocyte-derived dendritic cells. J Immunol. (2014) 193:1622-35. doi: 10.4049/jimmunol.1401243

23. Akira S, Uematsu S, Takeuchi O. Pathogen recognition and innate immunity. Cell (2006) 124:783-801. doi: 10.1016/j.cell.2006.02.015

24. van Vliet SJ, van Liempt E, Geijtenbeek TBH, van Kooyk Y. Differential regulation of C-type lectin expression on tolerogenic dendritic cell subsets. Immunobiology (2006) 211:577-85. doi: 10.1016/j.imbio.2006.05.022

25. van Vliet SJ, Paessens LC, Broks-van den Berg VCM, Geijtenbeek $\mathrm{TBH}$, van Kooyk Y. The C-type lectin macrophage galactose-type lectin impedes migration of immature APCs. J Immunol. (2008) 181:3148-55. doi: 10.4049/jimmunol.181.5.3148

26. Geijtenbeek TBH, Gringhuis SI. C-type lectin receptors in the control of T helper cell differentiation. Nat Rev Immunol. (2016) 16:433-48. doi: $10.1038 /$ nri.2016.55

27. Geijtenbeek TBH, Gringhuis SI. Signalling through C-type lectin receptors: shaping immune responses. Nat Rev Immunol. (2009) 9:465-79. doi: $10.1038 /$ nri2569

28. Monteiro J, Lepenies B. Myeloid C-type lectin receptors in viral recognition and antiviral immunity. Viruses (2017) 9:59. doi: 10.3390/v9030059
29. Akramien D, Kondrotas A, Did J, Egidijus K. Effects of b-glucans on the immune system. Medicina (2007) 43:597-606.

30. Feng D, Wang Y, Liu Y, Wu L, Li X, Chen Y, et al. DC-SIGN reacts with TLR-4 and regulates inflammatory cytokine expression via NF-кB activation in renal tubular epithelial cells during acute renal injury. Clin Exp Immunol. (2018) 191:107-15. doi: 10.1111/cei.13048

31. Gringhuis SI, den Dunnen J, Litjens M, van het Hof B, van Kooyk Y, Geijtenbeek TBH. C-type lectin DC-SIGN modulates toll-like receptor signaling via Raf-1 kinase-dependent acetylation of transcription factor NF-кB. Immunity (2007) 26:605-16. doi: 10.1016/j.immuni.2007.03.012

32. Gringhuis SI, Kaptein TM, Wevers BA, Mesman AW, Geijtenbeek TBH. Fucose-specific DC-SIGN signalling directs T helper cell type- 2 responses via IKK $\varepsilon$-and CYLD-dependent Bcl3 activation. Nat Commun. (2014) 5:1-13. doi: $10.1038 /$ ncomms 4898

33. Schnaar RL. Glycobiology simplified: diverse roles of glycan recognition in inflammation. J Leukoc Biol. (2016) 99:825-38. doi: 10.1189/jlb.3RI0116-021R

34. Harduin-Lepers A, Vallejo-Ruiz V, Krzewinski-Recchi MA, Samyn-Petit B, Julien S, Delannoy P. The human sialyltransferase family. Biochimie (2001) 83:727-37. doi: 10.1016/S0300-9084(01)01301-3

35. Varki A, Cummings RD, Esko JD, Stanley P, Hart GW, Aebi M, et al. Essential of Glycobiology. 3rd ed. Cold Spring Harbor, NY: Cold Spring Harbor Laboratory Press. Available online at: https://www.ncbi.nlm.nih.gov/ books/NBK310274/

36. Rillahan CD, Antonopoulos A, Lefort CT, Sonon R, Ley K, Dell A, et al. Global metabolic inhibitors of sialyl- and fucosyltransferases cory. Nat Chem Biol. (2012) 8:661-8. doi: 10.1038/nchembio.999

37. Kiwamoto $\mathrm{T}$, Katoh $\mathrm{T}$, Tiemeyer $\mathrm{M}$, Bochner $\mathrm{BS}$. The role of lung epithelial ligands for Siglec-8 and Siglec-F in eosinophilic inflammation. Curr Opin Allergy Clin Immunol. (2013) 13:106-11. doi: 10.1097/ACI.0b013e32835b594a

38. Johansson M, Kelly E, Nguyen C, Jarjour N, Bochner BS. Characterization of Siglec-8 expression on lavage cells after segmental lung allergen challenge. Int Arch Allergy Immunol. (2018) 177:16-28. doi: 10.1159/000488951

39. Jenner J, Kerst G, Handgretinger R, Müller I. Increased $\alpha 2,6$-sialylation of surface proteins on tolerogenic, immature dendritic cells and regulatory $\mathrm{T}$ cells. Exp Hematol. (2006) 34:1211-7. doi: 10.1016/j.exphem.2006.04.016

40. Maurer MA, Meyer L, Bianchi M, Turner HL, Le NPL, Steck M, et al. Glycosylation of human IgA directly inhibits influenza A and other sialic-acid-binding viruses. Cell Rep. (2018) 23:90-9. doi: 10.1016/j.celrep.2018.03.027

41. Inzana TJ, Balyan R, Howard MD. Decoration of Histophilus somni lipooligosaccharide with $\mathrm{N}$-acetyl-5-neuraminic acid enhances bacterial binding of complement factor $\mathrm{H}$ and resistance to killing by serum and polymorphonuclear leukocytes. Vet Microbiol. (2012) 161:113-21. doi: 10.1016/j.vetmic.2012.07.008

42. Schmidt CQ, Hipgrave Ederveen AL, Harder MJ, Wuhrer M, Stehle T, Blaum BS. Biophysical analysis of sialic acid recognition by the complement regulator Factor H. Glycobiology (2018) 28:765-73. doi: 10.1093/glycob/cwy061

43. Blaum BS. The lectin self of complement factor H. Curr Opin Struct Biol. (2017) 44:111-8. doi: 10.1016/j.sbi.2017.01.005

44. Angata T, Varki A. Chemical diversity in the sialic acids and related $\alpha$ keto acids: an evolutionary perspective. Chem Rev. (2002) 102:439-70. doi: $10.1021 / \mathrm{cr} 000407 \mathrm{~m}$

45. Varki A. Glycan-based interactions involving vertebrate sialic-acidrecognizing proteins. Nature (2007) 446:1023-9. doi: 10.1038/nature05816

46. Ali SR, Fong JJ, Carlin AF, Busch TD, Linden R, Angata T, et al. Siglec-5 and Siglec-14 are polymorphic paired receptors that modulate neutrophil and amnion signaling responses to group B Streptococcus. J Exp Med. (2014) 211:1231-42. doi: 10.1084/jem.20131853

47. Avril T, Attrill H, Zhang J, Raper A, Crocker PR. Negative regulation of leucocyte functions by CD33-related siglecs. Biochem Soc Trans. (2006) 34:1024-7. doi: 10.1042/BST0341024

48. Lehmann F, Gäthje H, Kelm S, Dietz F. Evolution of sialic acid-binding proteins: molecular cloning and expression of fish siglec-4. Glycobiology (2004) 14:959-68. doi: 10.1093/glycob/cwh120 
49. Angata T, Tabuchi Y, Nakamura K, Nakamura M. Siglec-15: an immune system Siglec conserved throughout vertebrate evolution. Glycobiology (2007) 17:838-46. doi: 10.1093/glycob/cwm049

50. Crocker PR, Gordon S. Properties and distribution of a lectin-like hemagglutinin differentially expressed by murine stromal tissue macrophages. J Exp Med. (1986) 164:1862-75. doi: 10.1084/jem.164. 6.1862

51. Angata T, Margulies EH, Green ED, Varki A. Large-scale sequencing of the CD33-related Siglec gene cluster in five mammalian species reveals rapid evolution by multiple mechanisms. Proc Natl Acad Sci USA. (2004) 101:13251-6. doi: 10.1073/pnas.0404833101

52. Barber EK, Crocker PR. Characterization of CD33 as a new member of the sialoadhesin family of cellular interaction molecules. Blood (1995) 85:2005-12.

53. Higuchi H, Shoji T, Iijima S, Nishijima KI. Constitutively expressed Siglec-9 inhibits LPS-induced CCR7, but enhances IL-4-induced CD200R expression in human macrophages. Biosci Biotechnol Biochem. (2016) 80:1141-8. doi: 10.1080/09168451.2016.1146070

54. Lock K, Zhang J, Lu J, Lee SH, Crocker PR. Expression of CD33-related siglecs on human mononuclear phagocytes, monocyte-derived dendritic cells and plasmacytoid dendritic cells. Immunobiology (2004) 209:199-207. doi: 10.1016/j.imbio.2004.04.007

55. Büll C, Collado-Camps E, Kers-Rebel ED, Heise T, Søndergaard JN, Den Brok MH, et al. Metabolic sialic acid blockade lowers the activation threshold of moDCs for TLR stimulation. Immunol Cell Biol. (2017) 95:408-15. doi: 10.1038/icb.2016.105

56. De Saint Jean A, Lucht F, Bourlet T, Delézay O. Transforming growth factor beta 1 up-regulates CD169 (sialoadhesin) expression on monocytederived dendritic cells: role in HIV sexual transmission. AIDS (2014) 28:2375-80. doi: 10.1097/QAD.0000000000000431

57. Nicoll G, Ni J, Liu D, Klenerman P, Munday J, Dubock S, et al. Identification and characterization of a novel Siglec, Siglec-7, expressed by human natural killer cells and monocytes. J Biol Chem. (1999) 274:34089-95. doi: 10.1074/jbc.274.48.34089

58. Angata T, Varki A. Cloning, characterization, and phylogenetic analysis of Siglec-9, a new member of the CD33-related group of Siglecs: evidence for co-evolution with sialic acid synthesis pathways. J Biol Chem. (2000) 275:22127-35. doi: 10.1074/jbc.M002775200

59. Zhang JQ, Nicoll G, Jones C, Crocker PR. Siglec-9, a novel sialic acid binding member of the immunoglobulin superfamily expressed broadly on human blood leukocytes. J Biol Chem. (2000) 275:22121-6. doi: 10.1074/jbc.M002788200

60. Li N, Zhang W, Wan T, Zhang J, Chen T, Yu Y, et al. Cloning and characterization of Siglec-10, a novel sialic acid binding member of the Ig superfamily, from human dendritic cells. J Biol Chem. (2001) 276:28106-12. doi: 10.1074/jbc.M100467200

61. Schwarz F, Landig CS, Siddiqui S, Secundino I, Olson J, Varki N, et al. Paired Siglec receptors generate opposite inflammatory responses to a humanspecific pathogen. EMBO J. (2017) 36:751-60. doi: 10.15252/embj.2016 95581

62. Cao H, Lakner U, de Bono B, Traherne JA, Trowsdale J, Barrow AD. SIGLEC16 encodes a DAP12-associated receptor expressed in macrophages that evolved from its inhibitory counterpart SIGLEC11 and has functional and non-functional alleles in humans. Eur J Immunol. (2008) 38:2303-15. doi: 10.1002/eji.200738078

63. Reineks EZ, Osei ES, Rosenberg A, Auletta J, Meyerson HJ. CD22 expression on blastic plasmacytoid dendritic cell neoplasms and reactivity of anti-CD22 antibodies to peripheral blood dendritic cells. Cytom Part B Clin Cytom. (2009) 76B:237-48. doi: 10.1002/cyto.b.20469

64. Crespo I, Paiva A, Couceiro A, Pimentel P, Orfão A, Regateiro F. Immunophenotypic and functional characterization of cord blood dendritic cells. Stem Cells Dev. (2004) 13:63-70. doi: 10.1089/154732804773099263

65. Thomas R, Lipsky PE. Human peripheral blood dendritic cell subsets. Isolation and characterization of precursor and mature antigen-presenting cells. J Immunol. (1994) 153:4016-28. Available at: http://www.ncbi.nlm.nih. gov/pubmed/7523513

66. Varki A, Angata T. Siglecs - the major subfamily of I-type lectins. Glycobiology (2006) 16:1-27. doi: 10.1093/glycob/cwj008
67. Bochner BS, Zimmermann N. Role of siglecs and related glycanbinding proteins in immune responses and immunoregulation. $J$ Allergy Clin Immunol. (2015) 135:598-608. doi: 10.1016/j.jaci.2014. 11.031

68. Wilhelm TR, Taddeo A, Winter O, Schulz AR, Mälzer JN, Domingo C, et al. Siglec-1-positive plasmacytoid dendritic cells (pDCs) in human peripheral blood: a semi-mature and myeloid-like subset imbalanced during protective and autoimmune responses. Clin Immunol. (2016) 163:42-51. doi: 10.1016/j.clim.2015.12.001

69. MacAuley MS, Crocker PR, Paulson JC. Siglec regulation of immune cell function in disease. Nat Rev Immunol. (2014) 14:653-66. doi: $10.1038 /$ nri3737

70. Cohen M, Varki A. The sialome-far more than the sum of its parts. Omi A J Integr Biol. (2010) 14:455-64. doi: 10.1089/omi.2009.0148

71. Varki A. Evolutionary forces shaping the Golgi glycosylation machinery: Why cell surface glycans are universal to living cells. Cold Spring Harb Perspect Biol. (2011) 3:1-14. doi: 10.1101/cshperspect.a005462

72. Crocker PR, Paulson JC, Varki A. Siglecs and their roles in the immune system. Nat Rev Immunol. (2007) 7:255-66. doi: 10.1038/nri2056

73. Avril T, Floyd H, Lopez F, Vivier E, Crocker PR. The membrane-proximal immunoreceptor tyrosine-based inhibitory motif is critical for the inhibitory signaling mediated by Siglecs-7 and-9, CD33-related Siglecs expressed on human monocytes and NK cells. J Immunol. (2004) 173:6841-9. doi: 10.4049/jimmunol.173.11.6841

74. Crocker PR, Redelinghuys P. Siglecs as positive and negative regulators of the immune system: figure 1. Biochem Soc Trans. (2008) 36:1467-71. doi: 10.1042/BST0361467

75. Walter RB, Häusermann P, Raden BW, Teckchandani AM, Kamikura DM, Bernstein ID, et al. Phosphorylated ITIMs enable ubiquitylation of an inhibitory cell surface receptor. Traffic (2008) 9:267-79. doi: 10.1111/j.1600-0854.2007.00682.x

76. Orr SJ, Morgan NM, Elliott J, Burrows JF, Scott CJ, McVicar DW, et al. CD33 responses are blocked by SOCS3 through accelerated proteasomal-mediated turnover. Blood (2007) 109:1061-8. doi: 10.1182/blood-2006-05-023556

77. Vitale C, Romagnani C, Falco M, Ponte M, Vitale M, Moretta A, et al. Engagement of p75/AIRM1 or CD33 inhibits the proliferation of normal or leukemic myeloid cells. Proc Natl Acad Sci USA. (1999) 96:15091-6. doi: 10.1073/pnas.96.26.15091

78. Lajaunias F, Dayer JM, Chizzolini C. Constitutive repressor activity of CD33 on human monocytes requires sialic acid recognition and phosphoinositide 3-kinase-mediated intracellular signaling. Eur J Immunol. (2005) 35:243-51. doi: 10.1002/eji.200425273

79. Backer R, Schwandt T, Greuter M, Oosting M, Jungerkes F, Tuting T, et al. Effective collaboration between marginal metallophilic macrophages and CD8+ dendritic cells in the generation of cytotoxic T cells. Proc Natl Acad Sci USA. (2010) 107:216-21. doi: 10.1073/pnas.0909541107

80. van Dinther D, Veninga H, Iborra S, Borg EGF, Hoogterp L, Olesek K, et al. Functional CD169 on macrophages mediates interaction with dendritic cells for CD8+T cell cross-priming. Cell Rep. (2018) 22:1484-95. doi: 10.1016/j.celrep.2018.01.021

81. Veninga H, Borg EGF, Vreeman K, Taylor PR, Kalay H, van Kooyk Y, et al. Antigen targeting reveals splenic CD169+macrophages as promoters of germinal center B-cell responses. Eur J Immunol. (2015) 45:747-57. doi: $10.1002 /$ eji.201444983

82. Higuchi H, Shoji T, Murase Y, Iijima S, Nishijima KI. Siglec-9 modulated IL4 responses in the macrophage cell line RAW264. Biosci Biotechnol Biochem. (2016) 80:501-9. doi: 10.1080/09168451.2015.1104238

83. Chen GY, Brown NK, Wu W, Khedri Z, Yu H, Chen X, et al. Broad and direct interaction between TLR and Siglec families of pattern recognition receptors and its regulation by Neul. Elife (2014) 3:e04066. doi: 10.7554/eLife.04066

84. Silva M, Silva Z, Marques G, Ferro T, Gonçalves M, Monteiro M, et al. Sialic acid removal from dendritic cells improves antigen cross-presentation and boosts anti-tumor immune responses. Oncotarget (2016) 7:41053-66. doi: 10.18632/oncotarget.9419

85. Nardy AFFR, Freire-de-Lima CG, Pérez AR, Morrot A. Role of Trypanosoma cruzi Trans-sialidase on the escape from host immune surveillance. Front Microbiol. (2016) 7:348. doi: 10.3389/fmicb.2016.00348 
86. Bornhöfft KF, Goldammer T, Rebl A, Galuska SP. Siglecs: a journey through the evolution of sialic acid-binding immunoglobulin-type lectins. Dev Comp Immunol. (2018) 86:219-31. doi: 10.1016/j.dci.2018.05.008

87. Erdmann H, Steeg C, Koch-Nolte F, Fleischer B, Jacobs T. Sialylated ligands on pathogenic Trypanosoma cruzi interact with Siglec-E (sialic acid-binding Ig-like lectin-E). Cell Microbiol. (2009) 11:1600-11. doi: 10.1111/j.1462-5822.2009.01350.x

88. Freire-de-Lima L, Alisson-Silva F, Carvalho ST, Takiya CM, Rodrigues MM, DosReis GA, et al. Trypanosoma cruzi subverts host cell sialylation and may compromise antigen-specific CD8+ T cell responses. J Biol Chem. (2010) 285:13388-96. doi: 10.1074/jbc.M109.096305

89. Carlin AF, Chang Y-C, Areschoug T, Lindahl G, Hurtado-Ziola N, King CC, et al. Group B Streptococcus suppression of phagocyte functions by proteinmediated engagement of human Siglec-5. J Exp Med. (2009) 206:1691-9. doi: 10.1084/jem.20090691

90. Carlin AF, Uchiyama S, Chang YC, Lewis AL, Nizet V, Varki A. Molecular mimicry of host sialylated glycans allows a bacterial pathogen to engage neutrophil Siglec-9 and dampen the innate immune response. Blood (2009) 113:3333-6. doi: 10.1182/blood-2008-11-187302

91. Khatua B, Bhattacharya K, Mandal C. Sialoglycoproteins adsorbed by Pseudomonas aeruginosa facilitate their survival by impeding neutrophil extracellular trap through siglec-9. J Leukoc Biol. (2012) 91:641-55. doi: $10.1189 /$ jlb.0511260

92. Izquierdo-Useros N, Lorizate M, Puertas MC, Rodriguez-Plata MT, Zangger N, Erikson E, et al. Siglec-1 is a novel dendritic cell receptor that mediates HIV-1 trans-infection through recognition of viral membrane gangliosides. PLoS Biol. (2012) 10:e1001448. doi: 10.1371/journal.pbio.1001448

93. Vanderheijden N, Delputte PL, Favoreel HW, Vandekerckhove J, Damme J Van, Woensel P A Van, et al. Involvement of sialoadhesin in entry of porcine reproductive and respiratory syndrome virus into porcine alveolar macrophages involvement of sialoadhesin in entry of porcine reproductive and respiratory syndrome virus into porcine alveolar macrophages. J Virol. (2003) 77:8207-15. doi: 10.1128/JVI.77.15.8207-8215.2003

94. Delputte PL, Nauwynck HJ. Porcine arterivirus infection of alveolar macrophages is mediated by sialic acid on the virus. J Virol. (2004) 78:8094101. doi: 10.1128/JVI.78.15.8094-8101.2004

95. Chang YC, Olson J, Louie A, Crocker PR, Varki A, Nizet V. Role of macrophage sialoadhesin in host defense against the sialylated pathogen group B Streptococcus. J Mol Med. (2014) 92:951-9. doi: 10.1007/s00109-014-1157-y

96. Byrd-Leotis L, Cummings RD, Steinhauer DA. The interplay between the host receptor and influenza virus hemagglutinin and neuraminidase. Int J Mol Sci. (2017) 18:1541. doi: 10.3390/ijms18071541

97. Heise T, Langereis JD, Rossing E, de Jonge MI, Adema GJ, Büll C, et al. Selective inhibition of sialic acid-based molecular mimicry in Haemophilus influenzae abrogates serum resistance. Cell Chem Biol. (2018) 25:1279-85.e8. doi: 10.1016/j.chembiol.2018.05.018

98. Bronikowska I, Swietochowska E, Oleksiak M, Czecior E. Sialic acids in head and neck squamous cell carcinoma. Postep Hig Med Dosw. (2016) 70:1300-8. doi: $10.5604 / 17322693.1227410$

99. Rodríguez E, Schetters STT, van Kooyk Y. The tumour glyco-code as a novel immune checkpoint for immunotherapy. Nat Rev Immunol. (2018) 18:204-11. doi: 10.1038/nri.2018.3

100. Borzym-Kluczyk M, Radziejewska I, Cechowska-Pasko M, Darewicz B. Reduced expression of E-cadherin and increased sialylation level in clear cell renal cell carcinoma. Acta Biochim Pol. (2017) 64:465-70. doi: 10.18388/abp.2015_1215

101. Pihikova D, Kasak P, Kubanikova P, Sokol R, Tkac J. Aberrant sialylation of a prostate-specific antigen: electrochemical label-free glycoprofiling in prostate cancer serum samples. Anal Chim Acta (2016) 934:72-9. doi: 10.1016/j.aca.2016.06.043

102. Zhang Z, Wuhrer M, Holst S. Serum sialylation changes in cancer. Glycoconj J. (2018) 35:139-60. doi: 10.1007/s10719-018-9820-0

103. Adams OJ, Stanczak MA, von Gunten S, Läubli H. Targeting sialic acidSiglec interactions to reverse immune suppression in cancer. Glycobiology (2017) 28:640-7. doi: 10.1093/glycob/cwx108

104. Kantarjian HM, DeAngelo DJ, Stelljes M, Martinelli G, Liedtke M, Stock W, et al. Inotuzumab ozogamicin versus standard therapy for acute lymphoblastic leukemia. N Engl J Med. (2016) 375:740-53. doi: 10.1056/NEJMoa1509277

105. Xiao H, Woods EC, Vukojicic P, Bertozzi CR. Precision glycocalyx editing as a strategy for cancer immunotherapy. Proc Natl Acad Sci USA. (2016) 113:10304-9. doi: 10.1073/pnas.1608069113

106. Büll C, Boltje TJ, Balneger N, Weischer SM, Wassink M, van Gemst JJ, et al. Sialic acid blockade suppresses tumor growth by enhancing $\mathrm{T}$ cell-mediated tumor immunity. Cancer Res. (2018) 78:3574-88. doi: 10.1158/0008-5472.CAN-17-3376

107. Büll C, Boltje TJ, Van Dinther EAW, Peters T, De Graaf AMA, Leusen JHW, et al. Targeted delivery of a sialic acid-blocking glycomimetic to cancer cells inhibits metastatic spread. ACS Nano (2015) 9:733-45. doi: $10.1021 / \mathrm{nn} 5061964$

108. Perdicchio M, Ilarregui JM, Verstege MI, Cornelissen LAM, Schetters STT, Engels S, et al. Sialic acid-modified antigens impose tolerance via inhibition of T-cell proliferation and de novo induction of regulatory T cells. Proc Natl Acad Sci USA. (2016) 113:3329-34. doi: 10.1073/pnas.1507706113

109. Orgel KA, Duan S, Wright BL, Maleki SJ, Wolf JC, Vichery BP, et al. Exploiting CD22 on antigen-specific B-cells to prevent allergy to the major peanut allergen ara h 2. Allergy Eur J Allergy Clin Immunol. (2017) 139:3669.e2. doi: 10.1016/j.jaci.2016.06.053

110. Perdicchio M, Cornelissen LAM, Streng-Ouwehand I, Engels S, Verstege MI, Boon L, et al. Tumor sialylation impedes T cell mediated anti-tumor responses while promoting tumor associated-regulatory T cells. Oncotarget (2016) 7:8771-82. doi: 10.18632/oncotarget.6822

111. Burchell J, Poulsom R, Handby A, Whitehouse C, Cooper L, Clausen H, et al. An alpha2,3sialyltransferase (ST3Gal I) is elevated in primary breast carcinomas. Glycobiology (1999) 9:1307-11. doi: 10.1093/glycob/9.12.1307

112. Gendler SJ, Lancaster CA, Taylor-Papadimitriou J, Duhig T, Peat N, Burchell J, et al. Molecular cloning and expression of human tumor-associated polymorphic epithelial mucin. J Biol Chem. (1990) 265:15286-93.

113. Beatson R, Tajadura-ortega V, Achkova D, Picco G, Tsourouktsoglou T-D, Klausing S, et al. MUC1 modulates the tumor immune microenvironment through the engagement of Siglec-9. Nat Immunol. (2016) 17:1273-81. doi: 10.1038/ni.3552

114. Ohta $\mathrm{M}$, Ishida $\mathrm{A}$, Toda $\mathrm{M}$, Akita $\mathrm{K}$, Inoue $\mathrm{M}$, Yamashita $\mathrm{K}$, et al. Immunomodulation of monocyte-derived dendritic cells through ligation of tumor-produced mucins to Siglec-9. Biochem Biophys Res Commun. (2010) 402:663-9. doi: 10.1016/j.bbrc.2010.10.079

115. Ishida A, Ohta M, Toda M, Murata T, Usui T, Akita K, et al. Mucin-induced apoptosis of monocyte-derived dendritic cells during maturation. Proteomics (2008) 8:3342-9. doi: 10.1002/pmic.200800039

116. Amadori S, Suciu S, Selleslag D, Aversa F, Gaidano G, Musso M, et al. Gemtuzumab ozogamicin versus best supportive care in older patients with newly diagnosed acute myeloid leukemia unsuitable for intensive chemotherapy: results of the randomized phase III EORTC-GIMEMA AML-19 trial. J Clin Oncol. (2016) 34:972-9. doi: 10.1200/JCO.2015.64. 0060

117. Castaigne S, Pautas C, Terré C, Raffoux E, Bordessoule D, Bastie JN, et al. Effect of gemtuzumab ozogamicin on survival of adult patients with de-novo acute myeloid leukaemia (ALFA-0701): a randomised, open-label, phase 3 study. Lancet (2012) 379:1508-16. doi: 10.1016/S0140-6736(12)60485-1

118. O’Hear C, Heiber JF, Schubert I, Fey G, Geiger TL. Anti-CD33 chimeric antigen receptor targeting of acute myeloid leukemia. Haematologica (2015) 100:336-44. doi: 10.3324/haematol.2014.112748

119. Minagawa K, Jamil MO, Al-Obaidi M, Pereboeva L, Salzman D, Erba HP, et al. In vitro pre-clinical validation of suicide gene modified anti-CD33 redirected chimeric antigen receptor T-cells for acute myeloid leukemia. PLoS ONE (2016) 11:e0166891. doi: 10.1371/journal.pone.0166891

120. Brentjens R, Davila ML, Riviere I, Park J, Cowell LG, Bartido S, et al. CD19-targeted $\mathrm{T}$ cells rapidly induce molecular remissions in adults with chemotherapy-refractory acute lymphoblastic leukemia. Sci Transl Med. (2013) 5:177ra38. doi: 10.1126/scitranslmed.3005930

121. Nerreter T, Köchel C, Jesper D, Eichelbrönner I, Putz E, Einsele $\mathrm{H}$, et al. Dasatinib enhances migration of monocyte-derived dendritic cells by reducing phosphorylation of inhibitory immune receptors Siglec-9 and Siglec-3. Exp Hematol. (2014) 42:773-82.e1-3. doi: 10.1016/j.exphem.2014.05.010 
122. Mustjoki S, Ekblom M, Arstila TP, Dybedal I, Epling-Burnette PK, Guilhot F, et al. Clonal expansion of T/NK-cells during tyrosine kinase inhibitor dasatinib therapy. Leukemia (2009) 23:1398-405. doi: 10.1038/leu.2009.46

123. Pang L, Macauley MS, Arlian BM, Nycholat CM, Paulson JC. Encapsulating an immunosuppressant enhances tolerance induction by Siglecengaging tolerogenic liposomes. ChemBioChem. (2017) 18:1226-33. doi: 10.1002/cbic.201600702

124. Büll C, Heise T, Adema GJ, Boltje TJ. Sialic acid mimetics to target the sialic acid-siglec axis. Trends Biochem Sci. (2016) 41:519-31. doi: 10.1016/j.tibs.2016.03.007

125. Prescher H, Schweizer A, Kuhfeldt E, Nitschke L, Brossmer R. Discovery of multifold modified sialosides as Human CD22/Siglec-2 ligands with nanomolar activity on B-cells. ACS Chem Biol. (2014) 9:1444-50. doi: $10.1021 / \mathrm{cb} 400952 \mathrm{v}$

126. Abdu-Allah HHM, Watanabe K, Completo GC, Sadagopan M, Hayashizaki $\mathrm{K}$, Takaku C, et al. CD22-antagonists with nanomolar potency: the synergistic effect of hydrophobic groups at C-2 and C-9 of sialic acid scaffold. Bioorg Med Chem. (2011) 19:1-16. doi: 10.1016/j.bmc.2011. 01.060

127. Collins BE, Blixt O, Han S, Duong B, Li H, Nathan JK, et al. High-affinity ligand probes of CD22 overcome the threshold set by cis ligands to allow for binding, endocytosis, and killing of B cells. J Immunol. (2006) 177:29943003. doi: 10.4049/jimmunol.177.5.2994

128. Spence S, Greene MK, Fay F, Hams E, Saunders SP, Hamid U, et al. Targeting Siglecs with a sialic acid-decorated nanoparticle abrogates inflammation. Sci Transl Med. (2015) 7:303ra140. doi: 10.1126/scitranslmed.aab3459

129. Gao PS, Shimizu K, Grant A V., Rafaels N, Zhou LF, Hudson SA, et al. Polymorphisms in the sialic acid-binding immunoglobulin-like lectin-8
(Siglec-8) gene are associated with susceptibility to asthma. Eur J Hum Genet. (2010) 18:713-9. doi: 10.1038/ejhg.2009.239

130. Nutku E, Hudson SA, Bochner BS. Mechanism of Siglec-8-induced human eosinophil apoptosis: role of caspases and mitochondrial injury. Biochem Biophys Res Commun. (2005) 336:918-24. doi: 10.1016/j.bbrc.2005.08.202

131. Zimmermann N, McBride ML, Yamada Y, Hudson SA, Jones C, Cromie KD, et al. Siglec-F antibody administration to mice selectively reduces blood and tissue eosinophils. Allergy Eur J Allergy Clin Immunol. (2008) 63:1156-63. doi: 10.1111/j.1398-9995.2008.01709.x

132. von Gunten S, Vogel M, Schaub A, Stadler BM, Miescher S, Crocker $\mathrm{PR}$, et al. Intravenous immunoglobulin preparations contain antiSiglec-8 autoantibodies. J Allergy Clin Immunol. (2007) 119:1005-11. doi: 10.1016/j.jaci.2007.01.023

133. Geh D, Gordon C. Epratuzumab for the treatment of systemic lupus erythematosus. Expert Rev Clin Immunol. (2018) 14:245-58. doi: $10.1080 / 1744666$ X.2018.1450141

Conflict of Interest Statement: The authors declare that the research was conducted in the absence of any commercial or financial relationships that could be construed as a potential conflict of interest.

Copyright () 2018 Lübbers, Rodriguez and van Kooyk. This is an open-access article distributed under the terms of the Creative Commons Attribution License (CC BY). The use, distribution or reproduction in other forums is permitted, provided the original author(s) and the copyright owner(s) are credited and that the original publication in this journal is cited, in accordance with accepted academic practice. No use, distribution or reproduction is permitted which does not comply with these terms. 